Maestros, Imágenes e Imaginarios

\section{Prácticas y saberes en}

\section{relación con la didáctica de}

\section{la imagen}

Teachers, images, and imaginaries

Practices and knowledge related to didactics of image

Professores, imagens e imaginário Práticas e conhecimentos sobre a didáctica da imagem

\section{Rafael Barragán Gómez*}

\section{Wilson Gómez Moreno*}

Magister en Estudios Semiológicos de la UIS. Docente adscrito a la Escuela de Idiomas de la Universidad Industrial de Santander, Bucaramanga, Colombia.

Correo electrónico: rbarraga@uis.edu.co

** Magister en Educación con énfasis en Lectura y Escritura de la Universidad Autónoma de Bucaramanga-Convenio Universidad Javeriana. Docente adscrito a la Escuela de Idiomas de la Universidad Industrial de Santander, Bucaramanga, Colombia. Correo electrónico: wilgomor@gmail.com

\section{Resumen}

El presente artículo es un avance del proyecto de investigación "Didáctica de la Imagen" que busca reconstruir los imaginarios de los maestros en torno a la imagen y los lenguajes verbo-visuales en dos instituciones educativas. Apoyado en una metodología etnográfica, el proyecto busca establecer la manera como tales imaginarios se articulan con unas prácticas educativas específicas en relación con estos objetos de aprendizaje dentro del contexto de la educación formal.

\section{Palabras Clave}

Imaginario, imagen, didáctica, etnografía, currículo.

\section{Abstract}

This article is an advance of the research project: " $\mathrm{Di}$ dactics of Image", which tries to find re-making the imaginaries of the teachers around images and oral-visual languages in two educational institutions. Supported on an ethnographic methodology, this project looks for establishing the way like those imaginaries are drawn together to some specific educational practices related to these learning objects into the context of formal education.

\section{Key Words}

Imaginaries, image, didactics of teaching, etnography, curriculum.

\section{Resumo}

Este artigo é um avanço do projeto de pesquisa Ensino a imagem, que visa reconstruir o imaginário dos professores em torno à imagem e às linguagens verbais $\mathrm{e}$ visuais em duas instituições de ensino. Baseado em um método etnográfico, o projeto visa estabelecer como se liga esse imaginário com práticas educativas específicas em relação a esses objetos de aprendizagem no contexto da educação formal.

\section{Palavras-chave}

Imaginário, imagem, etnografia, didáctica, currículo.

Fecha de recepción: 23 de marzo de 2010 Fecha de aprobación: 5 de junio de 2010

Este artículo es un avance del proyecto de investigación "Didáctica de la Imagen" patrocinado por la Vicerrectoría de Investigación y Extensión de la Universidad Industrial de Santander, UIS, y avalado por el Grupo de investigaciones ATENEA liderado por la Dra. Yolima Beltrán. 


\section{Introducción}

"Siempre miramos una manera de mirar, que además nos mira"

\section{G. Abril}

$\mathrm{E}$ l presente artículo es un avance del proyecto de investigación "Didáctica de la imagen" que, en su fase actual, intenta reconstruir los imaginarios de los maestros en torno a la imagen y los lenguajes verbo-visuales en dos instituciones educativas con población estudiantil de estratos socioeconómicos diferentes. Con base en este ejercicio etnográfico, se ha pretendido establecer la manera como tales concepciones inciden en la pervivencia de unas determinadas prácticas educativas en relación con estos objetos de aprendizaje dentro del contexto de la educación formal.

Aunque partimos del convencimiento de que la imagen y los sistemas que le son afines han estado presentes desde hace mucho tiempo en el aula (incluso desde los inicios de la escuela moderna), no deja de sorprender la incorporación tardía de los denominados "lenguajes no verbales" como objetos de enseñanza y aprendizaje en los Lineamientos Curriculares y en los Estándares para el área de Lengua Castellana; aspecto que, de algún modo, demanda una aproximación más sistemática a las maneras como tales sistemas de significación se perciben y abordan en el contexto escolar.

De igual modo, plantearemos algunos hallazgos iniciales de nuestra investigación etnográfica en el aula que nos llevan a considerar que las prácticas educativas de los maestros en relación con la imagen, con independencia del nivel socioeconómico de la institución donde laboran, de los recursos didácticos disponibles e, incluso, de su nivel de formación, están estrechamente ligadas a sus experiencias como aprendices, antes que a una fundamentación teórica rigurosa en relación con estos lenguajes.

Como consecuencia, se puede afirmar que las estrategias didácticas que recurren a la imagen se sustentan más en aproximaciones intuitivas, derivadas de la experiencia personal de los docentes, que a una racionalización de la complejidad e influencia de tales signos en la formación de los ciudadanos contemporáneos. Ello no implica necesariamente un efecto negativo en la calidad de la enseñanza, pero sí una limitación de las posibilidades que estos lenguajes pueden ofrecer a los procesos de formación; en especial, si se subvalora el papel que cumplen como detonantes de procesos de pensamiento complejos, los cuales solo se le han reconocido a la lectura y la escritura alfabéticas.
“Está claro que la imagen o signo visual, para utilizar una expresión más precisa, constituye una parte fundamental de la construcción de la memoria histórica de Occidente, al tiempo que ha sido un instrumento mediador sin precedentes para la consolidación de imaginarios colectivos."

El texto mostrará, asimismo, algunos aspectos de la formulación del problema de investigación, una justificación de la metodología utilizada, algunas precisiones en relación con el marco teórico que, de modo paralelo, se va desarrollando y unas conclusiones preliminares obtenidas a partir del material recolectado en el trabajo de campo.

\section{El problema}

En anteriores trabajos (Barragán, 2005) hemos insistido en la escasa fundamentación teórica con la cual, tanto los Lineamientos Curriculares para el área de lengua castellana (Ministerio de Educación Nacional 1998) como los Estándares para la misma área (MEN, 2003), justifican la necesidad de incorporar los llamados "lenguajes no verbales" a los currículos en el área de la lengua materna y la literatura. Esta limitación en las propuestas curriculares del Estado colombiano parece contradecir abiertamente el incontestable predominio global de los signos visuales en un mundo como el de hoy, que no por casualidad algunos teóricos de la imagen han denominado Iconósfera.

De esta situación paradójica pueden extraerse algunas conclusiones que, con toda probabilidad nos obligan a buscar explicaciones menos simplistas a la "ausencia" de la imagen como objeto de aprendizaje y al "predominio" de la cultura del texto escrito en la Escuela. Está claro que la imagen o signo visual, para utilizar una expresión más precisa, constituye una parte fundamental de la construcción de la memoria histórica de Occidente, al tiempo que ha sido un instrumento mediador sin precedentes para la consolidación de imaginarios colectivos. No en vano, la rica producción escultórica e icónica de la tradición religiosa católica, por citar un ejemplo, ha tenido una incidencia fundamental en buena parte de los procesos de evangelización y sostenimiento de la ideología cristiana dominante en el Nuevo Mundo (Gruzisnki, 2003). 
Ahora bien, el hecho de que en el aula su uso no traspase -aparentemente ${ }^{1}$ - lo decorativo o a lo sumo accesorio en los procesos de formación, puede explicarse inicialmente por dos aspectos: uno de orden tecnológico y otro de orden conceptual. En cuanto a lo primero, vemos que el acceso a la imagen impresa fue masivo sólo hasta finales del siglo XX; las imágenes que llegaban al aula antes de la primera mitad del siglo pasado eran escasas, aunque bastante influyentes en el plano ideológico. Paulatinamente, la aparición de las cartillas fue superando esta limitación, hecho que no incidió de manera significativa en que los maestros entraran a considerar las ilustraciones como objetos de enseñanza en sí misma².

A pesar del limitado valor atribuido a la imagen, las cartillas de lectura se constituyen en una evidencia importante del uso que los pedagogos y la Escuela le dieron a las ilustraciones, sin que hasta el momento se hayan considerado seriamente los efectos ideológicos que tuvieron dichas imágenes en la construcción de nuestros imaginarios sociales. Lo cual, sin duda, deberá ser tema de otro momento de la investigación.

El motivo de interés aquí reside en el hecho de que durante mucho tiempo la Escuela fue el escena-

1 Decimos "aparente" porque estamos convencidos de que, aunque una imagen no sea un objeto de trabajo en el aula explícitamente reconocido, la exposición permanente a ella, de manera inevitable moviliza procesos de percepción y, por ende, la modificación de estructuras cognitivas.

2 En el libro primero de "Alegría de Leer", hasta hace pocas décadas uno de los manuales de mayor difusión en nuestro medio, pueden apreciarse algunas consideraciones respecto del papel que debe jugar la imagen en la lectura:

En cuanto la variedad y la alegría de la clase así lo aconsejen, debe hacerse una conversación sobre el objeto representado por la palabra básica de la oración generadora de la cual se va a deducir el elemento nuevo de la respectiva lección. Esa conversación durará sólo lo necesario para fijar bien su significado e interesar al niño en conocer cómo se escribe la palabra, pues de lo contrario se convertiría la clase de lectura en lección de objetiva (sic), que corresponde a otra finalidad. En esto debe ser el maestro muy prudente para no abusar de los ejercicios de análisis" (...) Enséñese a los niños la figura que acompaña a cada vocal. Hágase una interpretación sencilla de ella para deducir el sonido de la vocal que se quiere enseñar y, una vez obtenido, se hará que los niños lo pronuncien de manera clara y en voz alta, asociando así el sonido a la idea. (...) Explíquese a los niños el proceso de la formación del signo escrito, y puede hasta buscársele alguna semejanza que pueda observar el niño directamente; por ejemplo, en la ilustración del ratón, la semejanza que tiene la posición de la cola con el rasgo final de la $i$, como también en el humo que sale de la pipa que fuma el indio. (...) Las ilustraciones del indio, la uña, el ojo, el ala, y el eje no se consideraran como palabras generadoras, sino como un auxiliar para ayudar a grabar en la memoria combinativa del niño el signo que se desea enseñar" Quintana, E. y Quintana, S. (1938). rio más importante para el consumo de imágenes, pero el desarrollo acelerado de nuevas tecnologías de la información y de artefactos para producir, reproducir, distribuir y consumir imágenes en tiempo real, incluso por encima de las barreras espaciales, sustituyeron rápidamente a esta institución.

La producción de imágenes, una actividad reservada a unos pocos escogidos, dio paso a una masificación de la producción que ha permitido que el ciudadano del siglo XXI, si tiene cierta pericia y un mínimo de equipos digitales, se convierta en creador de imágenes de excelente calidad, capaz de ponerlas en circulación prácticamente sin ningún costo (Sonesson, 2001).

Este hecho supondría la democratización del uso de la imagen, al tiempo que el sobrepaso de los límites imaginados para el intercambio de información. En efecto, Youtube, facebook y otro tipo de redes sociales son ejemplos contundentes del valor de la imagen como portadora de información; una información que no proviene, como pasaba hace apenas unos pocos años, de los grupos de poder que monopolizaban la producción y distribución iconográfica, sino del ciudadano del común que construye y reconstruye permanentemente, en el espacio virtual, nuevas formas de representación y, por ende, nuevas identidades (Bauman, 2005). No obstante, pese a que gran parte de ese impensable repertorio de imágenes circula y aporta simultáneamente nuevos datos e información, su capacidad para ejercer como medio privilegiado de control social es también mayor; y este poder se hace directamente proporcional al aumento progresivo de lectores más emotivos y estrictamente "literales", antes que críticos.

De otro lado, y en atención de la segunda consideración del problema planteado (es decir, la cuestión conceptual), tanto los maestros como un buen número de teóricos han reducido la imagen a la condición de simple referente, esto es, una representación meramente figurativa de otra realidad,

"Tanto los maestros como un buen número de teóricos han reducido la imagen a la condición de simple referente, esto es, una representación meramente figurativa de otra realidad, en lugar de considerarla un texto y una práctica discursiva en sentido estricto." 
en lugar de considerarla un texto y una práctica discursiva en sentido estricto. De este modo, se ha fortalecido la idea de que solo el texto verbal escrito permite la creación de conocimiento:

Recuerdo que una de las cosas que más insistían mis profesoras cuando ingresé a segundo de primaria era el que leyera libros que no tuvieran "matachitos", entiéndase, ilustraciones, porque eso podría distraer la atención. Aunque nunca estuve de acuerdo, no contaba con argumentos para defender la idea de que la imagen expone de manera autónoma un discurso y en la búsqueda de unas bases teóricas de mayor rigor, tuve que aceptar que la concepción de despreciar la imagen como portadora de conocimiento estaba fuertemente arraigada en la tradición pedagógica. Bruno Betthelheim cita en su libro "Aprender a leer" a Jeanne S. Chall (1967) quien afirma en "Learning to read: The great debate": "Nadie ha demostrado aún que los dibujos ayuden a reconocer las palabras o a comprender el texto. De hecho, experimentos recientes prueban que las ilustraciones pueden entorpecer los esfuerzos del niño en el intento de edificar una compresión. En cualquier caso, si la atención se ve desviada constantemente hacia los dibujos, puede que el principiante no se fije en las palabras y se haga una idea totalmente equivocada de en qué consiste la lectura." ${ }^{3}$

Ahora bien, la supuesta subordinación de lo visual a lo escrito no resulta de una condición servil de los signos visuales frente a la escritura alfabética sino del desconocimiento de los procesos complejos de pensamiento involucrados en la percepción visual, que consiste en algo más que un proceso pasivo de registro de estímulos luminosos y es, por el contrario, una actividad intelectual altamente compleja (Arnheim, 1998 y Aumont, 1992). Adicionalmente, serios estudios iconográficos, iconológicos e históricos demuestran que la interpretación de la imagen visual implica, como cualquier proceso lector, la ubicación en unas coordenadas espacio-temporales (Panofsky, 1980; Gombrich, 1999 y Burke, 2005).

En el proyecto que nos ocupa, el énfasis ha sido puesto en la manera como una inadecuada o insuficiente teorización acerca de los "lenguajes no verbales" -el nombre con el cual aparecen en los documentos oficiales, origen de múltiples confusiones (Colombia, Ministerio de Educación Nacional, 1989)- incide notablemente en unas determinadas prácticas pedagógicas y estrategias didácticas en el contexto del aula de clase que, por lo general,

3 Notas tomadas del diario de campo del investigador Wilson Gómez Moreno (2009). conducen a la reducción de los textos visuales a una condición instrumental, esto es, a las de mero recurso didáctico ideal para la motivación de los estudiantes.

Esta mirada reduccionista ha calado de tal forma en el medio escolar que incluso allí se pasan por alto, en especial en los niveles de básica secundaria, realidades tan evidentes como la influencia decisiva de la imagen en los procesos de iniciación del infante en la lectura y la escritura. Pocos maestros ignoran que en sus etapas iniciales, la lectura de textos alfabéticos se sustenta en la naturaleza icónica de los mensajes y que posteriormente ocurre la diferenciación entre el dibujo y la letra; es más, otros investigadores contemporáneos insisten en la necesidad reforzar las estrategias de enseñanza de la lectura a partir de imágenes aunque, debemos admitirlo, también incurren en la reducción de estos signos a una función instrumental dentro del aprendizaje de la lectura (Colomer, T. y Camps, A., 1996).

Así las cosas, si continúa ignorándose que en "la interpretación de los signos visuales no sólo se llevan a cabo complejos procesos receptivos sino que, adicionalmente, están implicadas operaciones cognoscitivas de orden superior que, en nuestra tradición, han estado circunscritas a los procesos mentales" (Barragán, R. y Gómez, W., 2010) 4 .

Esto quiere decir que se está desaprovechando el potencial didáctico, si se nos permite esta expresión, de los signos visuales dentro del aula, pues en su interpretación se hallan implicados procesos como exploración activa, selección, captación de lo esencial, abstracción, análisis, síntesis, completamiento, corrección, comparación, solución de problemas, combinación, separación y puesta en contexto (Arnheim, 1998). Procesos que se llevan a cabo cuando percibimos y que no se limitan a la esfera de los procesos mentales.

Sin embargo, el proyecto no pretende evaluar ninguna práctica pedagógica en particular; por el contrario, busca a partir de una reconstrucción cuidadosa de imaginarios en relación con la imagen y los medios audiovisuales en general, sistematizar estas observaciones de tal suerte que puedan reformularse para comprender algunas prácticas en el aula y, de paso, aprovechar el saber acumulado por las comunidades y equipos docentes en el esbozo de una didáctica que obtenga los mayores beneficios de este tipo de lenguajes.

\footnotetext{
4 Ver también, Barragán R. y Gómez, W. El lenguaje de la imagen y el desarrollo de los procesos superiores de pensamiento, [inédito] y Barragán, R. y Gómez, W. (2007).
}

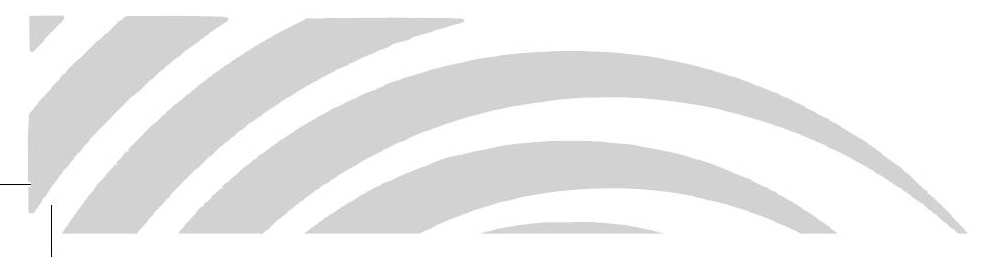


¿Qué definen los maestros como imagen? ¿Qué papel ha jugado la imagen en la construcción de conocimiento según su propia experiencia de formación? ¿Qué pasa con la imagen en el aula? ¿Cómo se trabaja? ¿Qué imaginarios apoyan el uso o la ausencia de trabajo con la imagen en las aulas? ¿Las condiciones sociales o económicas de las instituciones educativas pueden considerarse como una variable de peso a favor de la adecuada inclusión del trabajo con imágenes en el aula? Son algunas preguntas que buscamos responder en esta investigación.

Se espera, con las conclusiones que se obtengan del trabajo, avanzar en la elaboración de principios didácticos que validen el saber de los maestros, lo recontextualicen en el marco de teorías decantadas y permitan la formulación de una didáctica. Una didáctica de la imagen que postule los lenguajes sustentados en signos visuales como objetos de enseñanza y de aprendizaje en el ámbito de la educación formal, de tal manera que promuevan el desarrollo de procesos superiores de pensamiento como los descritos someramente en el apartado anterior y se aprovechen al máximo las posibilidades de la imagen en el desarrollo del pensamiento crítico. Esto supone una reconstrucción teórica paulatina que conecte las nociones de imagen, imaginario y desarrollo del pensamiento crítico en el aula.

\section{El método}

Una de las cualidades esenciales de la investigación etnográfica consiste en que pretende explicar el sentido de una práctica social a partir de la reconstrucción de los significados que los sujetos que participan de esa realidad le atribuyen. Al pretender reconstruir imaginarios -en el sentido dado al concepto en el marco teórico- y las prácticas de ellos derivadas, de manera necesaria se indaga por el sentido que tienen para los profesores los lenguajes sustentados en signos visuales y esto va atado no sólo a las actividades rutinarias del maestro sino a su historia de vida y sus experiencias personales, tanto como estudiante como profesional de la educación.

En tanto trabajo de interpretación, los instrumentos utilizados habitualmente en otros modelos de investigación proporcionarían información limitada en la medida en que las respuestas puntuales típicas y estandarizadas de las encuestas y muestreos con fines estadísticos no alcanzarían a explicar por sí solas las prácticas reales derivadas de concepciones profundamente arraigadas no solo en los maestros sino, también, en las comuni- dades de educadores (Hammersley, M. y Woods, P., $1995)^{5}$. De este modo apelamos a la entrevista en profundidad, con la cual pretendemos movilizar la construcción de un panorama muy amplio de la historia de vida de un grupo proyectado entre diez y veinte maestros (repartidos en cada colegio $\mathrm{y}$ vinculados voluntariamente al proyecto tras una etapa de sensibilización) que, esperamos, narren de la manera más completa posible el papel que jugaron los signos visuales en sus procesos de formación básica y de profesionalización y la presencia que tienen esos mismos recursos en su propio ejercicio docente. La información acá recogida se complementa con las observaciones hechas en los diarios de campo de los investigadores y un registro fotográfico de la iconografía predominante en los espacios físicos más importantes de cada una de las dos instituciones seleccionadas.

Se han escogido dos instituciones (una privada y otra pública), no tanto con el fin de establecer correlaciones entre variables socioeconómicas, sino con el propósito de someter a evaluación algunas de las consideraciones que se han hecho desde diferentes medios académicos y burocráticos en relación con la incidencia que tiene la infraestructura y la dotación escolar en los procesos de enseñanza y aprendizaje. Justamente, una de nuestras premisas sostiene que las llamadas prácticas pedagógicas, estrategias didácticas, etc. dependen en mayor medida de las experiencias de vida del maestro condensadas a lo largo de su proceso como aprendiz.

Luego de hacer el trabajo de recolección de información -entrevistas en profundidad y su respectiva transcripción- y del trabajo en los diarios se procede a la construcción de las categorías y las respectivas matrices para el análisis.

\section{Los conceptos de imagen e imaginario. Aproximaciones teóricas}

El concepto de imagen está comúnmente asociado al de icono; es decir, al de un signo relacionado con su objeto en virtud de la semejanza existente entre ellos. Si se tiene en cuenta que dicha relación icónica no es inmediata y que se encuentra mediada por la cultura, queda claro que esas representaciones, en apariencia naturales, son el resultado de formas convencionales de ver y que tales formas siempre hacen parte de un dispositivo (Aumont, 1992, p. 15),

5 Estos excelentes estudios etnográficos dan una visión muy completa del alcance de la investigación etnográfica para la comprensión de la cultura escolar. Hammersley, M. y Woods, P. (1995). 
de unos contextos sociales, institucionales, técnicos e ideológicos. Así pues, en cuanto admitimos la validez de esta afirmación, pasamos del ámbito de la visión al de la mirada (Abril, 2007, p. 48) ${ }^{6}$.

El concepto de mirada permite rebasar el marco estrecho que ha reducido la imagen a una clase de objeto que por ser inmediatamente perceptible por el sentido de la vista no demanda otra cosa distinta que la mera observación pasiva. Si se tiene en cuenta que los procesos perceptivos efectuados por el ojo involucran el despliegue de capacidades abstractivas, la percepción, entendida en estos términos, viene a ser mucho más que el registro pasivo de estímulos externos, como ya se dijo antes.

Aumont (1992) destaca esta condición de la mirada en tanto que es mucho más que un evento netamente fisiológico; en efecto, intenta demostrar que la percepción visual integra funciones psíquicas, la intelección, la cognición, la memoria, el deseo. Este investigador ha demostrado que la relación del aparato perceptivo con la luz hace parte del ámbito de lo visible; que la organización de lo visible por la percepción, en otras palabras, de la forma como tales estímulos se perciben como hechos situados en el espacio y en el movimiento constituiría lo visual. Esta categoría eminentemente humana implica al "sujeto que mira" y que lo hace modalizadamente (como alguien que quiere/sabe/puede ver).

Finalmente, se da el paso de lo visual a lo imaginario. Esta categoría remite a la representación; es decir, "a la cargazón epistémica, estética y simbólica de la experiencia visual" (Aumont, 1992, p. $35)^{7}$. Para Vitta (2003, p. 66 y ss.) lo imaginario, en relación con la imagen, surge allí donde la imagen ya no es concebida como la representación del mundo, sino del mundo concebido en cuanto imagen; con ello se pasa la representación de un espacio geométrico a la representación de un espacio simbólico con lo cual la imagen se convierte en "territorio de la subjetividad" y hace de la representación un elemento que media entre el pensamiento y la realidad.

6 También Aumont nos insiste en que "la mirada es lo que define la intencionalidad y la finalidad de la visión. No es, si se quiere, más que la dimensión propiamente humana de ésta" (1992, p. 62).

7 Este proceso se aprecia también en los tres niveles desarrollados desde la perspectiva de Durand para quien la experiencia visual se efectúa en tres niveles: el visual, que actúa en el ámbito de la percepción; el de la mirada, que concierne a la subjetivación, a las formas de mirar histórica y socialmente establecidas; y, finalmente, la dimensión imaginaria. Durand, Gilbert (2005). La imaginación simbólica. Buenos Aires, Amorrortu.
"El concepto de mirada permite rebasar el marco estrecho que ha reducido la imagen a una clase de objeto que por ser inmediatamente perceptible por el sentido de la vista no demanda otra cosa distinta que la mera observación pasiva."

Vitta insiste en que el imaginario posee un carácter eminentemente visual relacionado con las formas de representación colectiva en una época determinada que van más allá de la experiencia. Los imaginarios conforman "un agitado magma de expectativas, voluntades, miedos, aspiraciones, creencias y convicciones ampliamente compartidas que empujan a la conciencia -individual y colectiva- con una fuerza explosiva e inconsciente hasta sus límites, orientando en gran medida nuestro comportamiento" (2003, p. 67).

Tanto influye el imaginario en nuestras concepciones de mundo que las imágenes "que nos formamos de las cosas no son más que representaciones de una realidad inerte en sí misma, pero que cobra vida ante nuestros ojos gracias a los contenidos que nosotros mismos introducimos extrayéndolos de las profundidades de nuestra personalidad individual y colectiva, esto es, de nuestro imaginario" (2003, p. 68).

Por ello, las imágenes se convierten en representaciones por cuanto a través de ellas vamos más allá de su contenido real y las interpretamos gracias al filtro que nos proporciona el imaginario. Es este el valor simbólico de las imágenes. Rojas afirma que "toda imagen se revela como un sistema de representaciones y como un objeto exterior que el espectador interpreta desde su banco de imágenes y con referencia a su cultura semiótica" (2006, p. 41).

Como puede deducirse de las anteriores reflexiones, la imagen, en general, y los medios audiovisuales, en particular, juegan un papel importante en la configuración y establecimiento de los llamados imaginarios en la vida moderna. Para Rojas, "estudiando la trayectoria que da lugar a la aparición del mundo visual contemporáneo, Michel Foucault hablaba de genealogía de lo visual. Las partes constituyentes de la cultura visual no están constituidas por el medio, sino por la interacción entre el espectador y la imagen" (2006, p. 42).

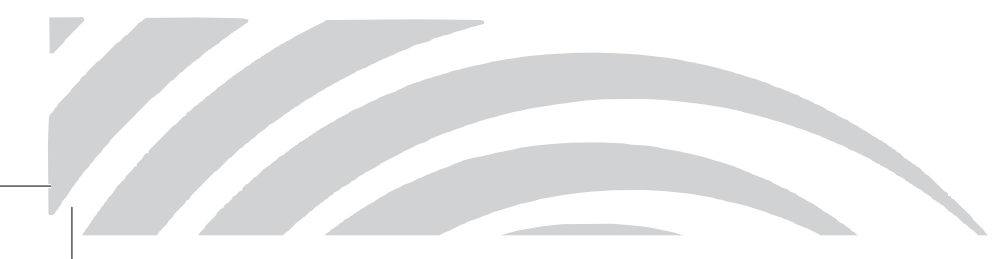


Esto es, precisamente, lo que hemos denominado como el tránsito de lo visual a lo imaginario. En este sentido, en la parte final intentaremos hacer una integración de estas concepciones sobre el imaginario con las ideas de Ch. Taylor (2006), para quien un imaginario social es, antes que nada, un sistema compartido que garantiza la vida social en todos aquellos ámbitos donde no nos podemos desempeñar según una teoría.

Estas categorías, así definidas, nos proporcionan una base teórica razonable para aproximarnos a la cultura escolar. Aproximación dada no solamente en razón de las creencias que sustentan ciertas prácticas pedagógicas en torno a la imagen visual o a los lenguajes verbovisuales sino, también, como lo hemos visto, al conectar los conceptos de imagen e imaginario de una perspectiva para abordar comprensivamente ciertos procesos que caracterizarían las tensiones propias de la Escuela en este contexto globalizado donde, sin duda alguna, la imagen ha recobrado un papel preponderante.

\section{La didáctica de la imagen en dos instituciones educativas de Bucaramanga: hallazgos preliminares y discusión}

Los primeros hallazgos del trabajo etnográfico en las instituciones educativas estudiadas nos permiten establecer las siguientes consideraciones: Un primer aspecto para tener en cuenta en nuestra investigación se relaciona con la exploración de la manera como la imagen ha hecho parte de la vida personal y profesional del maestro, pues consideramos que no puede operarse una reorientación en las prácticas pedagógicas de las comunidades educativas si se desconocen el saber acumulado por los docentes, sus imaginarios y la manera como estas creencias se trasladan a los procesos de enseñanza y de aprendizaje. En este sentido, los maestros entrevistados señalan que, efectivamente, han tenido experiencias de formación donde la imagen ha estado presente pero, con contadas excepciones, solo de manera marginal y con una clara orientación instrumental aun cuando reconocen su valor como detonante o "estímulo" para movilizar la atención y el interés hacia textos escritos especialmente.

Si bien los maestros utilizan los lenguajes verbo visuales y los textos visuales, en particular, no hay una conceptualización de los procesos semióticos involucrados en la producción y consumo de significados, ni tampoco un abordaje crítico donde se analicen los procesos mediante los cuales dichos textos configuran unas prácticas discusivas históricamente situadas. Se destaca, por ejemplo, la importancia del cine y la televisión, pero se detectan pocas experiencias de abordajes didácticos sistemáticos donde el discurso planteado en el medio sea el eje de los procesos.

La relación uso/valor de la imagen está fuertemente arraigada a la idea de utilización del medio, en especial del medio audiovisual: televisión, cine e Internet. Aunque es inevitable que se haga esta asociación, se ha de destacar que los niveles de percepción, de asimilación discursiva y de impacto cognitivo son distintos de acuerdo tanto con el recurso tecnológico, el soporte o el formato en sí mismos como con el conjunto de estas variables asociadas, así como de la propia enciclopedia del espectador. En términos de recepción, no es lo mismo una imagen en una valla, que una imagen en Google o en televisión, los tiempos de exposición, la posibilidad de volver sobre un momento particular del enunciado o sobre un fragmento, el lugar donde se encuentre expuesta, las intenciones comunicativas y, en fin, todas estas variables modifican los alcances de asimilación literal e inferencial, pero apenas se esbozan tímidamente por los entrevistados.

No se hace frecuente que el maestro mencione el uso que hace de la imagen como objeto decorativo; tampoco es común que reconozca en ella el proceso de enunciación que le es inherente por el hecho de ser el resultado de una práctica discursiva; menos aún que se problematice explícitamente los complejos procesos de producción y reproducción ideológica implicados en la enunciación visual. La imagen consiste en un "recurso didáctico" sólo cuando se presenta en un momento determinado de clase, de ahí que no se tenga en cuenta, por ejemplo, el impacto que, en términos de formación, pueden llegar a tener la cartelera escolar, los cuadros de honor, los afiches que ambientan ciertos espacios, la iconografía religiosa y, en fin, tantas otras imágenes que seguramente han sido puestas allí con la intención de comunicar un contenido especifico y que se mantienen aparentemente inadvertidas.

Podríamos plantear una hipótesis preliminar en relación con esta condición, más bien gregaria, de la imagen frente al texto soportado alfabéticamente, no sólo en el ámbito escolar, sino en el de la vida cotidiana. Creemos que, a partir de lo expresado por los maestros, puede inferirse un imaginario fuertemente consolidado en Occidente que ha confinado lo visual a lo meramente figurativo, ignorando o pretendiendo ignorar su dimensión plástica. Esta tensión explicaría la causa de la ansiedad o la desazón que produce el arte conceptual en el común 
de los espectadores quienes, presas de una especie de "ilusión figurativa", tienden invariablemente a buscar un referente claramente identificable en las señales visuales de una pintura, por poner un ejemplo.

Aun cuando no se ha consolidado la construcción de categorías dentro de este proyecto, consideramos que lo que es válido para la cultura en general lo es, mutatis mutandi, para la cultura escolar. En efecto, siempre ha resultado un esfuerzo particularmente difícil tratar de delimitar con claridad el lindero entre las experiencias vitales del maestro y los rumbos que suelen tomar sus opciones pedagó-

\section{"Cualquier didáctica, más que un} ejercicio de aplicación de técnicas y principios relativamente estandarizados que afectan las formas de enseñar y concebir los objetos de aprendizaje, debe partir de un reconocimiento de la condición de sujetos sociales e históricos de los maestros como principales agentes del proceso educativo"

\section{Bibliografía}

Abril, G. (2007), Análisis crítico de textos visuales. Mirar lo que nos mira, Madrid, Síntesis.

Aryzpe, E. y Styles, M. (2004), Lectura de imágenes. Los niños interpretan textos visuales, México, Fondo de Cultura Económica.

Arnheim, R. (1998), El pensamiento visual, Barcelona, Paidós.

Aumont, J. (1992), La imagen, Barcelona, Paidós.

Barragán, R. (2005), "Presencia de los lenguajes no verbales en el área de lengua castellana”, ponencia presentada al primer Seminario y Coloquio sobre Didácticas de las Lenguas y la Literatura, Cali: UnivalleRed Latinoamericana para la Transformación de la Formación Docente en Lenguaje. gicas, pues cualquier investigación en este sentido suele concluir que existe un continuum que impide discernir entre estos ámbitos. Este trabajo continúa en su intento por mostrar un caso particular de retroalimentación entre las experiencias de vida y las labores propias del profesional de la educación, referidas a los signos visuales los cuales, de manera curiosa, no han suscitado el mismo interés que los discursos verbales como agentes forjadores de los imaginarios en los maestros.

Pese a que el concepto de imaginario alude a la forma como un grupo "imagina" su entorno social y expresa dichas representaciones por medio de historias, leyendas y, muy especialmente, de imágenes (Taylor, 2006, p. 38), éstas no han sido estudiadas con el rigor y la extensión dedicados a los discursos verbales. Por ello, no sólo consideramos la imagen en tanto objeto o instrumento del que se tiene más o menos conciencia dentro de las instituciones educativas, sino también de la imagen como vehículo y génesis de tales imaginarios. Con ello, reafirmamos nuestra convicción de que cualquier didáctica, más que un ejercicio de aplicación de técnicas y principios relativamente estandarizados que afectan las formas de enseñar y concebir los objetos de aprendizaje, debe partir de un reconocimiento de la condición de sujetos sociales e históricos de los maestros como principales agentes del proceso educativo.

Barragán, R. y Gómez, W. (2007), "La caricatura como herramienta para el desarrollo del pensamiento crítico", ponencia presentada al VI taller latinoamericano para la transformación de la formación docente en lenguaje, I Coloquio latinoamericano sobre didáctica del español como lengua materna, las lenguas extranjeras y la literatura y III encuentro de didáctica de la literatura, Cali: Univalle-Red Latinoamericana para la Transformación de la Formación Docente en Lenguaje.

Barragán, R. y Gómez, W. (2010), El lenguaje de la imagen y el desarrollo de los procesos superiores de pensamiento, [inédito].

Bauman, Z. (2005), Identidad, Buenos Aires, Losada.

Burke, P. (2005), Visto y no visto. El uso de la imagen como documento histórico, Barcelona, Crítica. 
Colombia, Ministerio de Educación NACional. (1989), Lineamientos curriculares. Lengua Castellana, Bogotá, Magisterio.

Colomer, T. y Camps, A. (1996), Enseñar a leer y enseñar a comprender, Madrid, Celeste/MEC.

Gombrich, E.H. (1999), Los usos de las imágenes. Estudios sobre la función social del arte y la comunicación visual, México, Fondo de Cultura Económica.

Gruzinski, S. (2003), La guerra de las imágenes. De Cristóbal Colón a "Blade Runner" (1492-2019), México, Fondo de Cultura Económica.

Hammersley, M. y Woods, P. (edits.) (1995), Género, cultura y etnia en la escuela. Informes etnográficos, Barcelona, Paidós.

Panofsky, E. (1989), El significado en las artes visuales, Madrid, Alianza.
Quintana, E. y Quintana, S. (1938), La alegría de leer, Cali, Voluntad.

Rojas, F. (2006), El imaginario: civilización y cultura del siglo XXI, Buenos Aires, Prometeo Libros.

Silva, A. (2006), Imaginarios urbanos, Bogotá, Arango Editores.

Taylor, Ch. (2006), Imaginarios sociales modernos, Barcelona, Paidós.

Sonesson, G., Semiótica cultural de la sociedad de imágenes. De la reproducción mecánica a la producción digital, [en línea], disponible en: http://www.arthist. lu.se/kultsem/semiotics/kult.sem.sp.html, recuperado: 10 de agosto de 2001.

Vitta, M. (2003), El sistema de las imágenes, Barcelona, Paidós. 